\title{
Experiencing stigma as sex work researchers in professional and personal lives
}

Journal article submission to: Sexualities (2014)

\author{
Natalie Hammond \\ University of Manchester, UK \\ Sarah Kingston \\ Leeds Metropolitan University, UK
}

\begin{abstract}
Researchers have demonstrated the challenges associated with sex work research; negotiating the stigma attached to its subject matter, the perceived dangerousness of participants, and the barriers faced in reaching hidden populations. By reflecting upon our separate research experiences and drawing upon a body of reflexive sex work research, this article explores how, as sex work researchers, we experienced stigma not only in our professional roles as researchers, but also in our personal lives. We apply Goffman's (1968) notion of stigma by association; and consider how stigma often associated with prostitution became transposed onto us. In particular, we compare and contrast our separate experiences of conducting sex work research to demonstrate our similar experiences of stigma by association.
\end{abstract}

Keywords

Reflexivity, sex work research, stigma 


\section{Introduction}

This article is based upon our separate experiences of conducting research into the UK sex industry. Both authors engaged in research reflexivity, which is now considered to be a significant part of conducting research, as researchers are encouraged to scrutinize their own actions and role in the research design and process (Blaikie, 2000). From this reflexive practice and subsequent discussions, we discovered that we both experienced stigma from our involvement in sex work research. Our experience supports previous academic work in this area, but also demonstrates how stigma can be experienced in researchers' personal lives and is not solely limited to the research context.

In particular this article will explore how we as sex work researchers experienced the stigma commonly related to sex work: we experienced 'stigma by association'. By considering Goffman's (1968) work on the 'spoiled identity' we demonstrate how our close relationship with our topic of study became a vehicle by which sex work stigma spread onto us. Our experience of negative or critical responses to our work shares some similarities to the treatment of sex workers. As with the 'whore stigma' that sex workers often face, our research was seen as dishonourable and 'no good' (Pheterson, 1993). The notion that, as Lowman (2000) suggests, sex workers are considered 'undeserving victims' became fused with us as sex worker researchers that led to colleagues and those in our personal spheres to question the validity of someone studying an 'undeserving topic'. Our original contribution is that our comparative discussion not only provides an individualistic account of stigma, an approach that Parker and Aggleton (2003) argue dominates much work on stigma, but also that we move to include an exploration of structural issues and those who do the stigmatizing within our discussion.

\section{Sex work, Stigma and Identity}

Commercial sex can be seen as a stigmatized activity, and those who take part are constructed as different, challenging societal, sexual and moral norms. Paying for sex invokes an identity that lies outside the boundaries of prescribed sexual behaviour, resulting in an associated 'stigma' of fear, disapproval, rejection and shame, if revealed to those outside the industry (Sanders, 2008). The 
strength of this stigma can present significant, emotional and material penalties, Goffman's (1968) classic work, and newer work by Link and Phelan (2001), help to make sense of this.

Goffman describes stigma 'as an attribute that is deeply discrediting ... [involving] a relationship between attribute and stereotype' (1968: 13-14). A person with, or lacking, a certain attribute is categorized as a less desirable, devalued individual with a spoiled identity. This attribute is a stigma, made up of the difference between one's actual identity (attributes one does possess) and one's virtual identity (assumptions about who s/he ought to be; Goffman, 1968: 2). Goffman highlights the difference between the discredited (the difference is known about or easily visible) and the discreditable (it is either unknown or not instantly perceivable). If the characteristic becomes known to others the individual moves from discreditable to discredited, suggesting that one may try to manage knowledge of this characteristic.

In dealing with a discredited character Goffman (1968) focuses on techniques that are used to conceal behaviour and not reveal the 'truth' about oneself. If an individual is discreditable, but their difference is unknown to others, the issue is not managing tension within the interaction, but managing information 'to display or not to display; to tell or not to tell . . . to lie or not to lie' (1968: 57). For example, Sanders (2008) describes the discreditable male clients of sex workers as passing, this is 'the management of undisclosed discreditable information about the self' (Goffman, 1968: 58). However, if the individual is discredited covering is put into action, 'an effort to keep the stigma from looming large ... reduce tension . . . ease matters for those in the know' (1968: 125).

Work drawing on Goffman has been criticized for promoting an individualized theory of stigma in which stigma is a thing, a negative attribute, a static, rather than a changing social process, which is mapped onto people who then become devalued because of their difference (Parker and Aggleton, 2003). Link and Phelan (2001) critique more current work on stigma noting its lack of conceptual clarity and application, and for an absence of accounts of experience. They argue that most work on stigma is individualistic, ignoring structural issues and focusing on those who do the stigmatizing. Consequently, they propose a new model of stigma. Drawing on Goffman's position, which explains stigma as the relationship between an attribute and a stereotype, Link and Phelan (2001) develop the notion of the relationship, seeing it in terms of the way the distinguishing and labelling of human differences take place in line with dominant cultural beliefs, linking labelled persons to undesirable characteristics. Those labelled are separated into distinct categories, creating an 'us' and 'them' dichotomy. 
Utilising Link and Phelan's (2001) work, it is apparent from sex work literature that there are deeply ingrained cultural attitudes and perceptions of those involved in the sex industry which can often lead to stigma. The behaviour and activities of female sex workers and clients is generally thought to be immoral, anti-social and deviant (see Sanders, 2008). 'Women are allowed to give free sex but not to negotiate sex without defying a host of laws. A woman who earns money through sex is defined as selling her honor' (Pheterson, 1993: 43).

Male clients are categorized as different to men who have multiple non-commercial sexual partners, and this difference is socially constructed as deviant and intolerable, contributing towards paid-for sex as a stigmatized activity (Sanders, 2008). Media discourses about kerb crawling construct 'clients as dehumanized, dirty and animalistic' (Campbell and Storr, 2001: 98). These labels originate in cultural and religious discourses concerning the place and role of sex in society: the differentiation between good and bad sexual behaviour, and the undermining of the specialness of sex in commercial sex (Sanders, 2008: 115-116).

Our research experiences support this structural analysis of stigma. We both experienced similar feelings of being stigmatized for researching a controversial topic. Given that our research was conducted on different aspects of the sex industry and in different towns and cities in the UK, we argue that the commonalities between our research experiences demonstrate the impact dominant cultural beliefs have on those researching sex work. The next section examines the importance of engaging in research reflexivity, as it is in the context of this process that we recognized these experiences.

\section{Reflexivity in sex work research}

Reflexive practice has risen up research agendas and the social context in which knowledge is produced has begun to be acknowledged. Feminist methodologists have argued that knowledge is contextually specific and the researcher's biography affects what they find out, and, therefore what we know (Stanley and Wise, 1993). Research is not undertaken in a vacuum, and researchers cannot claim to be neutral, detached or objective from the social world we study: our thoughts, feelings, experiences and behaviours are influenced by wider society and our own individual biographies, which can affect research findings (Hammersley and Atkinson, 2007; Mason, 2002). Asking difficult questions and engaging in reflexive practice enables researchers to critically evaluate their role within the research context. As Maher explains: 
The boundaries between reflexivity and self-indulgence are fragile and blurred

and ... 'confessional tales' can also position the self firmly within the field of

study ... I was no longer the medium through which fieldwork was conducted but

part of the story. (2002: 316)

Sex work researchers have begun to discuss their research experiences and document their reflective accounts, by including themselves into the analysis to 'expose ... the relations that influence the construction of the story that is told' (Presser, 2005: 2087). Emotional labour and negative emotions, which may be ignited during sex work research, have been documented (Melrose, 2002; O'Connell Davidson and Layder, 1994; Sanders, 2006). Other methodological problems such as gaining ethical approval, managing prevailing stereotypes, and researcher safety during research encounters in the field, begin to reveal some of the discrediting attributes associated with sex work research (Melrose, 2002; O’Neill, 1996; Sanders, 2006; Shaver, 2005).

The reflexive insights of other sexuality researchers reveal the professional difficulties facing those whose work explores issues surrounding sex and sexuality including being viewed as an illegitimate, thrilling or taboo topic, as a joke, or as unworthy study, all of which can result in loss of professional status, present barriers to career progression and leave researchers vulnerable to inappropriate remarks, personal abuse and being regarded as 'not very bright and sexually available' (Attwood, 2010: 179). Speaking of sex may be seen as crude, can encourage suspicion and could even be dangerous for one's professional reputation (Attwood, 2010: 178). Attwood goes further to argue that 'despite a belief that in late modern societies we are 'incited' to speak about sex, tensions and silences still persist and some types of speech and speakers are strongly discouraged' (2010: 178). Sex research upsets the constructed divide between public and private and potentially raises questions about 'what kind of a woman' does such research? (Braun, 1999: 368).

\section{Research experiences}

This article is based upon our separate experiences of researching the UK sex industry. Kingston's (2009) project, which considered those who lived in areas known for street prostitution, explored community attitudes towards men who buy sex, interviewing residents, business employees, the 
police and local authority officials in a large northern city (see Kingston, 2013). The second study researched men who buy sex, interviewing male clients about their experiences of sexuality and relationships in both commercial and non-commercial contexts (Hammond, 2010b). Both projects focused upon male clients, but from different perspectives. The following section begins by looking at our identity within the professional sphere, exploring the role of gender and perceptions of us as professional researchers. The discussion moves on to consider the importance of reflexive practice beyond the research context to explore our wider social lives and everyday interactions. Of particular importance is our role and identity as Sex Work Researchers. By exploring the work of Goffman $(1959,1968)$ we consider how our researcher identity became fused with our personal identity, and how we employed stigma management strategies and presented ourselves in a particular manner.

\section{Experiencing stigma as a researcher}

\section{Danger and risk}

Our gender as women alongside our connections with the sex industry, and (potentially) meeting these 'dangerous others' prompted fears for our personal safety. In both cases we were warned, by friends, family, colleagues and peers about the dangers we potentially faced as women researching this topic. Kingston was warned, by residents, police officers and local councillors, about the dangers she potentially faced as a woman conducting research in a well-known red-light district. For instance, whilst attending a community partnership meeting to discuss local issues, her fieldwork notes demonstrated some of these concerns:

... I was warned about being in the area late at night by a councillor and resident ... a male resident told me to take care on my own in the area... [he] talked about how his ex-girlfriend was propositioned by kerb-crawlers whilst waiting for a bus.

Concerns were also raised for Hammond's personal safety within the ethical review process and in her personal life. For instance people questioned if she would have a bodyguard, or if there would be someone else sitting in the room when interviewing these 'dangerous' men in her university department (see Hammond, 2010a). Hammond's emotional safety, the potential of hearing stories of abuse and violence was a concern of others, but also Hammond herself. Her initial reading around the sex industry presented a gloomy picture of violence, risk, drug taking and exploitation, thus in addressing ethical concerns around potential harm to the researcher Hammond thought it important 
to take measures to be emotionally prepared for the worst. For example, Hammond thought that reading research into sexual violence and male violence against women may help her deal with uncomfortable and shocking narratives that both she and others assumed would arise.

Our experiences of being warned of the risks and dangers we faced as female researchers may be further understood through the work of Link and Phelan (2001). In line with dominant cultural beliefs, the male client label invites the undesirable characteristics of danger and violence: characteristics different from 'ordinary' men (Link and Phelan, 2001). Applying Schoepf's (2001) argument surrounding those with HIV and the way they are marked as different and then stigmatized, those associated with the sex industry are placed in a risk category, separated from other identities and only categorized through their stigmatized attribute and seen as a 'dangerous other'. Serial murderers of sex workers in the UK such as the Yorkshire Ripper, Ipswich Ripper and Crossbow Cannibal inflated concerns that male clients are potentially violent, dangerous man (Kingston, 2010; Kinnell, 2008; Sanders and Campbell, 2009). These events have led to stereotypes and myths about the danger and risk male clients pose to street sex workers and women more generally, and were identified in Kingston's (2013) research when community groups discussed the dangers sex workers experience when working in the sex industry. Although research has highlighted the violence and dangers associated with sex work, and street sex workers are at a greater risk of violence (Kinnell, 2008) women are more likely to be attacked or killed by the (ordinary) men they know (Brittan, 2011; Zaplin, 2008). Although real events, the high profile murders of sex workers in the UK have exaggerated the dangers clients may pose. The 'deviant' male client is portrayed as predator who needs to be guarded against, external to the community of 'normal' men - an outsider who is untrustworthy and dangerous' (Cowburn and Dominelli, 2001: 401). A man who buys sex is thus seen as 'a blemished person, ritually polluted, to be avoided, especially in public places' (Goffman, 1968: ii). This was projected onto us as female researchers and our research became stigmatized, separated into a distinct category labelled dangerous and risky.

Gaining ethical approval in this context can therefore be fraught with challenges as cultural anxieties about sex may disadvantage research projects in this area. Those who make decisions about whether a project will be awarded ethical approval do not live in a vacuum and are equally influenced by the culture that stigmatizes sex work research. These issues arose in Irvine's (2012) study where researchers identified how sometimes Institutional Review Boards (IRBs) viewed projects which explored sexuality as too risky because they considered the researcher to be vulnerable. For example, a female sociologist identified how the IRB approval for her study of people 
who self-identify as 'kinky', stated that she was not permitted to attend a respondent's home because it would not be safe.

Irvine reflected upon the decisions often made by Institutional Review Boards (IRBs), which she argues 'play a significant but largely unnoticed role in the marginalization of sexuality research' (2012: 29). As she explains, those research projects that are accepted and institutionally recognized are merely the tip of the iceberg of suppressed research plans. Irvine argued that 'Sexuality has been a "special case" .. . falling among a few topics automatically deemed "sensitive" and therefore generally subject to enhanced scrutiny in IRB deliberations. Consequently, IRBs operate as bureaucracies of sexuality simultaneously constraining sexual knowledge while reinforcing sexual stigma' (2012: 29). Irvine's research highlighted that IRB practices, according to the researchers she spoke with, had either slowed down or discouraged their research. As a result, some researchers stated that they gave up attempting to conduct research on sexualities. Neither author of this article experienced such significant constraints however, as Hammond's experiences revealed, in preparing for and addressing the concerns of her University Ethical Review Board, those who pay for sex were constructed by the Board as 'needing to be protected from', and also, as 'in need of protection' due to their stigmatized identity.

\section{The researchers' sexuality}

The sexualization and threat to the female researcher are documented in the literature (Lee, 1997; Pini, 2005). Moreno's (1995) account of being raped in the field starkly highlights the vulnerabilities women face. Huff (1997), however calls attention towards the possible sexualization of the researcher in a more subtle manner. In her research with adults with severe mental health disabilities she experienced 'attention [which] consisted of unwanted romantic overtures, such as touching, hugging, poking and comments such as "hey hot lips"', in addition to receiving gifts (1997: 117). In the context of sex work, Grenz (2005), at the beginning of her research into male clients recalls significant sexualization from potential participants. She received requests including to be allowed to masturbate, for her to wear a short skirt and for men to expose their penises to her.

As female researchers researching the topic of sex work, our gender was also a factor in how some male participants responded to us. Kingston found her identity as a female sex work researcher may have labelled her as 'different' as sexually liberal, compared to other women not associated with the sex industry but 'similar' to those involved in selling sex. These assumptions were then transformed 
'into normative expectations ... making certain assumptions as to what the individual before us ought to be' (Goffman, 1968: 12).

During Kingston's research, a male senior police officer sent her a sexually explicit message offering her casual sex following an interview:

Yeah was cool to meet one so chilled and open minded - don't let the gay thing put $u$ off if you fancy a bit of casual sex (just don't tell the bf!) Defo give me a shout though l'll settle for coffee $x$.

Sanchez Taylor and O'Connell Davidson argue that the stigma attached to a sexual practice that is popularly regarded as deviant can extend to those who conduct such research (2010: 50). Because of Kingston's engagement with sex work research, the assumption that sex workers always consent to sex, have sex with strangers and with many partners became transposed onto her (Miller and Schwartz, 1995; Pheterson, 1993; Sullivan, 1995). It appeared that 'the problems faced by stigmatized persons spread out in waves' and as sex workers are assumed to be always sexually available, as was Kingston, they experience stigma by association (Goffman, 1968: 43).

Zurbriggen's (2002) work on relationships and sexuality led to her being propositioned which suggests 'participants might assume that because the researcher is studying sexuality she must be sexually interested or available (2002: 262). Zurbriggen (2002) notes these experiences of sexualization have been discussed by other researchers in terms of sexual harassment as Huff (1997) reveals, or as a misinterpretation of female friendliness and sexual interest by male participants. Such encounters also happen to male researchers. Baum recalls the confusion some female participants displayed about the nature of their relationship: 'When she began to suggest that I should spend the night in her compound ... similar confusions developed with women informants .. . who seemed to hope my interests were not purely academic' (2008: 160). The cultural context in which research operates is central and both Baum (2008) and Rubenstein (2004) discuss the communities, in which they undertook anthropological work, having significant concerns about them finding a wife from within the communities they studied. Rubenstein recalls being persistently asked why he did not marry a local female; which he found disturbing as most of the local females were under 16. As Walby explains, despite a researchers' intention to be seen as a professional researcher, the participants may not view you in this regard:

As much as the researcher positions as a sociologist, the respondent may position the researcher as a sex object. My body as a researcher ... is part of this milieu of 
sexualisation ... Gestures interpreted as non-sexual may be taken in another direction. For instance, I purposefully wore business attire for the interviews ... the intention was to seem professional and asexual, my appearance could have been interpreted otherwise. (2010: 650)

For Hammond, the potential of receiving unwanted sexual attention was a key concern for her, the university and for those in her personal life (see Hammond, 2010a). The ethical procedures she laid out to protect herself, as the researcher, from harm included downplaying feminine characteristics by dressing plainly and formally with no makeup and if necessary, she was prepared to make herself sexually unavailable (see Huff, 1997). Despite these risk aversion strategies Hammond did not have to deflect any unwanted sexual attention. This reveals Hammond's own anxieties and how she herself also drew on dominant stereotypes about male clients and those associated with the sex industry, but perhaps more critically than those around her, because for her, these men were not that dangerous that she could not be in the same room with them alone (see Hammond, 2010a).

Even though Hammond was not propositioned, assumptions were made about her sexual attitude and past, signifying an associated whore stigma (Pheterson, 1993). An email dialogue after fieldwork from a participant is revealing:

I have a question but I am not quite sure if I should ask it? ... I was wondering if you have worked in the sex industry?

Other participants were intrigued about Hammond's motivations for researching the sex industry, frequently asking at the end of interviews why she had chosen such a topic: perhaps a less explicit method of evaluating if she had previously been involved in selling sex? Reavey's work on child sexual abuse, presented similar questions 'why research such a depressing topic - what's in it for you? (1997: 553). Assumptions were made about potential skeletons in her closet; she recalls a phone call where it was inferred that she herself had been abused and that is why she was researching this (Reavey, 1997). The motivations for selling and buying sex are one of the most widely researched topics surrounding sexual commerce. In parallel, Hammond's motivation as a researcher entering this topic was also questioned; why would she as an (assumed) honourable woman choose to research the dishonourable and unworthy (Pheterson, 1993)? Why would anyone (researcher/ male client/sex worker) choose to be associated with such an undesirable industry? Male researchers have similarly identified assumptions and expectations made about them as men researching sex and sexuality. Assumptions made about the interests of male researchers in their 
topic, or perversions that they may have (which were considered to have ultimately led them to research their topic) have been highlighted somewhat, although further discussions in this area are needed. For instance, Angelides (1998) identified how whilst undertaking his research into paedophilia he was contacted by a private investigator who was working with Queensland Australia's law enforcement body. When Angelides questioned why he had been contacted, the investigator explained that he should not worry as the investigation was 'not interested in the activities of an individual paedophile', instead they were pursuing those 'involved in "organised" paedophile activities', implying that he, as a lone paedophile was not under investigation. Kirby and Corzine (1981) also revealed similar levels of stigma. Whilst working as a student researcher on a study around homosexuality, one of the authors also undertook part-time work at a local mental health hospital. When he was spotted by a fellow employee leaving a gay bar this resulted in suspicion and discrimination. He was denied requests to take male patients on community visits and private therapy sessions were continuously interrupted; staff had cast him in the stereotypical role of a 'predatory homosexual intent on seducing the hospital's young male patients' (1981: 7).

\section{Fear and scepticism}

We both encountered participants and or gatekeepers who appeared concerned about our research, fearful of the impact it may have upon themselves and the area where they lived or worked. Stigmatization and desire for anonymity have been a key concern for potential participants; Plumridge et al. (1997) for example stated that the majority of their participants, men who paid for sex, declared they had never told anyone about their activities before. The stigma female sex workers face is well documented, making obvious the reasons why participation in sex work research may not be an attractive proposition (see Sanders, 2005; Scrambler, 2007).

Hammond negotiated this by offering MSN instant messenger interviews, which participants felt would protect their identity more than face to face or telephone interviews. These potential participants were fearful of the negative consequences of being associated with the sex industry, while these men may be discreditable because of their involvement in paid-for sex, this may be unknown to the wider world or not instantly perceivable. Therefore, in order to take part in the research they had to strategically offer the information of this 'undisclosed discreditable information' (Goffman, 1968: 58). As Goffman argues, not all social situations are the same and MSN online interviews allowed participants to 'pass' by managing the disclosure of discreditable information whilst still 'covering' and keeping the stigma from looming large. 
Kingston found that her participants were concerned about her presence in one area and some declined from the research at later stages. For them, there was a fear of being associated with prostitution; people did not want prostitution to be associated with their neighbourhood, they were sceptical of her presence and the attention she might have brought to their area (Kingston, 2013). It was clear they were aware that the stigma associated with prostitution may be linked to themselves, their homes and their families. As Link and Phelan (2001) explain, these residents drew on dominant cultural beliefs about prostitution being associated with dirt, danger and immorality, fearing they themselves would become labelled with similar undesirable characteristics, labels that could be troublesome to remove. Residents did not want to 'live within the world of one's stigmatized connexion' (Goffman, 1968: 43).

Kingston found accessing some participants through her gatekeepers problematic. Unlike Hammond who received full support, authenticity and endorsement from her gatekeeper (Hammond, 2010b), Kingston found that gatekeepers to particular members of community groups, strung her along and attempted to deter her from speaking to members of a community centre group. The gatekeepers felt that it was inappropriate to talk about prostitution at one community centre because there were children present and the centre has religious connections, despite its members' desire for Kingston to continue attending the sessions they frequented. Local councillors also attempted to put her 'off the scent' by telling her that the problem of prostitution was no longer an issue in one area of a city. Yet, immediately after a community meeting where this comment was made, a resident approached her to tell her that this was untrue, and that the problem was still very much an issue for local residents. This male participant believed that the local council were concerned that Kingston's presence and research may raise people's awareness that the area of the city was known for street prostitution.

It was apparent that because there were concerns that the stigma associated with prostitution may spread, participants attempted to avoid or terminate any involvement in Kingston's research (Goffman, 1968). In doing so they were engaging in what have been defined as 'stigma management strategies' in order to reduce or eliminate being associated with stigmatized groups. In particular, concerns that the stigma Goffman describes as blemishes to a person's moral character may be transposed onto them was challenged through avoidance behaviour. As sex workers and their clients do not conform to social norms surrounding sexuality, their transgression of the moral boundaries leads them to be considered as deviant, (Duncan, 1996); residents did not want themselves or the area they lived in to be associated with such immorality. 
Given the likelihood of experiencing stigma outside of academia, as we have suggested, we believe reflexive practice should extend beyond the research encounter and consider the interaction between the research context and the researcher's wider everyday life, for research is never undertaken in a vacuum, thus everyday experiences can lead to a greater understanding of the society in which research is located. For example, Plummer's (1995) notion of sexual stories, in which the researcher is part of the process of constructing the story and thus becomes part of the process of constructing sexual knowledge, suggests that the story produced is interwoven within life stories, resulting in 'personal narratives that are socially embedded in the daily practices of everyday life' (1995: 15).

\section{An unworthy job}

Those whose research explores sexuality often report marginalization and discrimination from those within and outside academia (Attwood, 2010; Israel, 2002). Mattley's study into the commercialization of emotions using phone sex workers found her funding application denied and one reviewer stated 'there must be another occupation to study ... Was it chosen simply because it was titillating?' (1997: 104). More recently Sanders suggests she met similar hurdles and begins her book about research with male clients by claiming the topic had 'no time to wait for funding or be trampled down by the prudery of the academy or inflated concerns about ethics' (2008: vii). The fact that sex work research may not be taken seriously within and beyond academia suggests there is something fundamental about sex work research itself, which leads it to be seen as an unworthy topic for academic scholarship.

The feeling that some people who were not directly involved in our research field, either as a participant, peer or colleague, viewed our topic and our jobs as researchers as a 'joke' and 'unworthy' of academic research was an experience we both had outside of the data collection context. Some people disbelieved that we studied prostitution, and were so shocked by our declaration that they initially seemed stunned, asking us to repeat the statement or questioning whether we were telling the truth. We witnessed and became the focus of laughter, jokes and ridicule, with many people finding it 'funny' that we, as women were studying prostitution.

Emotional labour in the research process has been well documented as mentioned earlier (see Hammond, 2010a; Melrose, 2002; Sanders, 2006, 2008) but for us, instead of participants' responses providing the challenge it was the response of others outside of the research context that had to be managed (Braun, 1999; Israel, 2002). Mattley reveals the emotional labour required to address 
others' reactions in terms of secrecy and the constant justification that sexuality research may involve:

I'm not sure if they are really fascinated by the idea of doing something weird or forbidden or what ... I resolve not to talk to anyone else about this research. Other people's reactions make me uncomfortable and I need to focus on the research itself, not explaining myself and why I'm not a voyeur to everyone!! (Mattley, 1997: 109)

Hammond recalls a similar uncomfortable event at which several people who knew about her work informed others that she was 'doing a PhD on prostitution' with the 'humorous' undertone that she herself was a sex worker and would be involved in selling sex. There was a diminishing of her academic identity and the serious nature of her work, as Mattley (1997) also experienced. Kingston also often found her friends would inform people they met that she was undertaking a PhD into prostitution because they enjoyed observing their shocked and sometimes horrified reactions.

Similarly, from her experience of researching female strippers, Israel found being introduced as 'This is Tania - she has a degree in sex' disconcerting and as if her association with sexuality research overshadowed all other aspects of her life (2002: 257). Israel felt unable to choose whether or not her identity as a sex worker researcher was revealed, as others often displayed it for her. Her participants also identified how they too were mindful of whom they told they worked as a stripper. Likewise Hammond discovered that her male participants had similar issues about to whom to reveal their involvement in paid-for sex and we experienced similar dilemmas about revealing our sex work research identity. Just as paying for sex lies outside of the boundaries of acceptable sexual behaviour and moral conduct and selling sex is seen as a dishonourable way to earn a living, research into such a topic is also held in less regard. We often also found ourselves being cast into 'one camp or another', in that the polarized positions towards prostitution of radical and liberal feminism became acted out in our everyday lives. This argument 'constructs sex work as either exploitive or liberating and, sex workers as coerced victims or empowered whores' (Wahab, 2002: 265; see also Weitzer, 2009). It was often assumed that we must have a political or theoretical motivation for studying prostitution and many people that we met would often engage in debates about the place for prostitution in society. For some people, their views echoed a radical feminist position that prostitution was the 'absolute embodiment of patriarchal privilege' (Kesler, 2002: 219), and should thus be eradicated, whilst for others prostitution was deemed an acceptable form of work and 
should be regulated (Weitzer, 2005). Often these debates would involve people labelling prostitution or those involved as 'dirty', 'diseased', 'shameful' or 'dangerous. In this sense, some believed our research to be unworthy because prostitution should not exist to be researched.

We did not experience extreme hostility or abuse as sex workers and those assumed to be sex workers may (see Sharpe, 2000) and it is important to take note of Israel's point 'Although the level of stigma I experienced was far less than that of the dancers experienced, I none the less could empathize with the experience of information being shared without my consent' (2002: 257). Researchers can go home and 'the stigma for the academic is however, far less severe because conducting research on sexuality is considered more legitimate than participating in the experiences that we study' (Israel, 2002: 256). We found that when we 'went home' and although our position as a researcher is considered more legitimate, we still experienced stigma because of our associations with prostitution. Although we went home, researchers rarely do a 9am-5pm working day, and often our work is taken home. As with 'the loyal spouse of a mental patient, the daughter of an excon, the parent of the cripple, the friend of the blind, the family of the hangman' we were 'obliged to share some of the discredit of the stigmatized person to whom they are related' (Goffman, 1968: 30). Therefore, stigma management strategies may need to extend beyond the boundaries of 'home life', as the boundaries between it and 'working life' are often blurred.

\section{Managing the spoiled identity}

Although we did not share the same social position as sex workers or their clients we similarly felt the need to employ strategies to cope with our role as sex work researcher and the reactions of people to us. As Sanders's research with female sex workers showed, they often employed strategies to keep their work a secret. For her participants 'secrecy is crucial because sex workers fear disapproval, rejection and shame' (Sanders, 2005: 116). Male clients also attempt to keep their behaviour hidden and have been reluctant to engage in research through fear of embarrassment and the potential negative impact on their personal relationships (Brooks- Gordon and Gelsthorpe, 2003; Earle and Sharp, 2008; Faugier and Sargeant, 1997; Klein, et al., 2008; Sanders, 2008). Similarly, we also in some way sought to keep our research a secret.

To manage this 'spoiled identity', we chose to manage knowledge about our sex work researcher identity balancing the level of information we gave about our research topics in different contexts (Goffman, 1968). We followed many of Goffman's (1968) techniques to avoid being cast as different to other researchers. We employed stigma management strategies of withdrawal, withdrawing from 
any discussions on our research topic and on occasions, going even further to conceal and deny our involvement in sex work research similar to Mattley's (1997) approach. The notion that anyone could, or would want to, research not just the sex industry, but to choose to speak to the men who pay for sex themselves in the case of Hammond's research, proved shocking for some. She had to assess the potential reaction of the people around her, their attitude towards sex, the sex industry and men who pay for sex, and their reaction to her before she chose to reveal her association with commercial sex. This was tiresome and hard work and often she avoided revealing that she was even involved in any research at all.

We both felt reluctant to identify or discuss the nature of our research with people we did not know, with Hammond telling people her work was about gender or relationships, or 'nothing interesting' and Kingston explaining that her research explored public attitudes. We concealed stigma symbols through not talking about the true nature of our research, presented the stigma symbol as a sign of another less stigmatized attribute by choosing not to disclose being a 'sex work researcher' and instead introduced our research as exploring gender or relationships. Our intention was to conceal information about our real social identity, a strategy Goffman defines as 'passing' (1968: 58). We also attempted to present ourselves in particular ways, intentionally and consciously controlling how we presented ourselves to others (Goffman, 1959). In particular, during discussions and debates about our research discipline, we often presented ourselves as uninterested in the topic of discussion. In this way, we mounted a performance to project ourselves in a particular manner, managing and negotiating 'the presentation of the self' (Goffman, 1959).

Not all encounters necessitated such practices. We split the world into those who knew nothing and those who knew all; supervision was one of many backstage locations where there was no need to conceal the stigma (Goffman, 1968). In some cases other practices were needed. During interviews Hammond's association with the sex industry was known, so she did not have to manage this; both she and her participants shared this characteristic. By taking part in sex talk with many strangers, as a woman, taking control of such encounters, and being seen as an expert on sex/sex work by virtue of doing a PhD on the topic, Hammond thought other attributes associated with sex workers could have been ascribed to her and participants may have mistaken her for a sex worker, or behaved in a similar way as they would during paid-for sex encounters (Pheterson, 1993: 46). In parallel, she sought to minimize the way participants who have been constructed as perverts and sexually forward could react to her. By managing normal routines (Goffman, 1968) she performed a certain identity, that of a sexually uninspiring female, reducing her feminine characteristics by removing makeup and wearing a neutral outfit. Despite asking questions about sexuality she was trying to 
minimize the potential that participants would find her sexually desirable and respond inappropriately. Hammond thought managing the embodied and visible nature of the stigmatized attributes - dishonourable, sexually available woman - would allow her to be seen as a professional researcher doing serious work. Similarly, Kingston chose to dress in a particular way, ensuring that she wore 'smart' clothing in order to distinguish herself as a professional researcher, especially when walking the streets in the area she conducted research.

\section{Conclusion}

This article has explored how we as sex work researchers experienced stigma commonly associated with prostitution in both our professional lives as researchers and also in our private everyday lives. As Hammond (2010a) argues, it is only with a distance from the field that the space to reflect becomes available. It is the physical and emotional distance from the research that may enable a researcher to put things into perspective (Bernard, 1988). Our experiences of sex work research have highlighted a number of important issues for current and potential sex worker researchers. We have shown that reflexivity should be undertaken in both the traditional sense considering the researcher-researched relationship, and also more widely to include researchers' more immediate social and professional lives. Reflexive practice may reveal how some interactions with other people can be valuable for research as they can inform the researcher of the ways in which resistance and denial can take shape in everyday life. Reflecting on how people receive the topics and communities being researched can serve as a useful resource for connecting our experiences and for recognizing resistance to the topics under study in everyday life and academia (Reavey, 1997: 557).

The experience of stigma ran throughout both our experiences. Not only did we observe and face stigma in the research context, we similarly encountered stigma in our personal social lives. This is important as it reveals something crucial about sex work, (and perhaps other research on sexuality), that those who study this topic may face similar discrimination as sex workers and their clients. Our experiences of having the credibility and worthiness of our work about the sex industry challenged led us to empathize with the experiences of sex workers and their associates. As Goffman (1968) suggested, those who are closely connected with a stigmatized person or group often experience the same social stigma. Researching a stigmatized topic led to us being associated with the negative attributes and assumptions made about prostitution, albeit in a less discriminatory manner. By reflection upon our experience, we recognized and appreciated the reasons why sex workers and 
their clients often employed coping strategies to keep their commercial sex and non-commercial lives distinct and separate.

Despite the stigma we feel we have faced, it has in no way deterred us from researching this area. We both continue to enjoy researching sex work and sexuality more broadly, and accept that sometimes people's reactions to us and our research are not always as we hope or expect. In our academic careers we somewhat continue to be the focus of jokes and scepticism. For instance, at meetings with academic colleagues Kingston has often been asked about her research and laughter about the topic of study frequently arises. As with one of Irvine's (2012) respondents, she too has been said to be 'obsessed with sex'. However, unlike researchers who took part in Irvine's (2012) study, we have not yet faced difficulties in terms of promotion or a move to other areas or institutions.

Despite these experiences, we fully recognize that these reactions are data in themselves and tell us a great deal about the social context in which we conduct our research. The experiences we have gained have led us to reflect upon the nature of the topic and helped us to understand the stigma often discussed in academic texts and identified by sex workers themselves.

We have highlighted the importance of Goffman's (1968) work to explain the means through which we attempted to manage our own 'spoiled identity'. With this in mind, we felt compelled to write this reflective account of our experiences in the hope that other researchers may become more aware of how the challenges of researching prostitution can be used as data, informing the research project and the researcher of the context in which their research topic is located. Research training, should therefore, encourage researchers, male and female, to consider both the research and much wider social and personal implications of research. Furthermore, this awareness may enlighten researchers to the value of data gathered from our non-research experiences as we continue to recognize our place in the social world.

\section{Acknowledgements}

We would like to thank the three anonymous reviewers for their helpful comments. We would also like to thank Nick Frost and Rosie Campbell for taking the time to read and comment on this article whilst it was in progress.

Bibliography 
Angelides S (1998) The Threat of Paedophilia, Reading Australia 1998, University of Adelaide, 13 November 1998.

Attwood F (2010) Dirty work: researching women and sexual representation. In Ryan-Flood R and Gill R (eds) Secrecy and Silence in the Research Process. London: Routledge, 177-187.

Baum R (2008) From a Boy Not Seeking a Wife to a Man Discussing Prophetic Women. A male fieldworker among Diola women in Senegal 1974-2005. Men and Masculinities 11(2): 154-163.

Bernard H R (1988) Research Methods in Cultural Anthropology. Newbury Park, CA: Sage.

Blaikie N (2000) Designing Social Research. Cambridge: Polity Press.

Blagden, N. And Pemberton, S. (2010) The Challenge in Conducting Qualitative Research with convicted Sex Offenders. The Howard Journal 49(3): 269-281.

Braun V (1999) Breaking a Taboo? Talking (and laughing) about the vagina. Feminism and Psychology 9(3): 367-372

Brittan D M (2011) The gender of Crime. New York: Rowman and Littlefield Publishers

Brooks-Gordon B and Gelsthorpe L (2003) Prostitutes' Clients, Ken Livingstone and a New Trojan Horse. The Howard Journal 42(5): 437-451.

Campbell R and Storr M (2001) Challenging the Kerb Crawler Rehabilitation Programme. Feminist Review 67, 94-108.

Cowburn M and Dominelli L (2001) Masking hegemonic masculinity: reconstructing the paedophile as the dangerous stranger. British journal of social work 31(3), 399-414.

Duncan N (1996) Introduction, In: Duncan N (ed) (Re)Placings, London: Routledge.

Edelstein J 2007 'Why second-wave feminism has gone soft', Public Policy Research SeptemberNovember 2007, [Online November] Available at:

http://www.engender.org.uk/UserFiles/File/news/Jean\%20Edlestein\%20article.pdf [accessed 23 April 2008] 164-167.

Earle S and Sharp K (2008) Intimacy, pleasure and the men who pay for sex. In Letherby G, Williams K, Birch P and Cain M (eds) Sex as Crime. Cullumpton: Willan Publishing, 63-79.

Fallen D (2008) The "Other" Gender? Reflections on Fieldwork in Benin. Men and Masculinities 11(2): 164-173.

Faugier J and Sargeant M (1997) Boyfriends, "Pimps" and Clients. London: Routledge.

Goffman E (1959) The Presentation of Self in Everyday Life. New York: Anchor Books.

Goffman E (1968) Stigma: Notes on the management of spoiled identity. Middlesex: Penguin Books. 
Grenz S (2005) Intersection of sex and power in research on prostitution: a female researcher interviewing male heterosexual clients. Signs: Journal of Women and Culture in Society 30(4): 20912113.

Hammersley M and Atkinson P (2007) Ethnography: Principles in practice, 3rd edition. London: Routledge.

Hammond, N. (2007) University Research Ethics Form. University of Sheffield

Hammond N (2010a) Tackling Taboos: men who pay for sex and the emotional researcher. In: Hardy K, Kingston S and Sanders T (eds) New Sociologies of Sex Work, Farnham: Ashgate, 59-74.

Hammond N (2010b) Paying for Sex: A socio-cultural exploration of sexual commerce. Unpublished Doctoral thesis: University of Sheffield.

Home Office (2008) Tackling the Demand for Prostitution: A review. [online] Available at: http://www.homeoffice.gov.uk/documents/tackling-demand [Accessed on: 12th December 2008]

Huff J (1997) The sexual harassment of researchers by research subjects: lessons from the field. In: Schwartz M (ed.) Researching Sexual Violence against Women: Methodological and Personal Perspectives. London: Sage, 115-128.

Irvine Janice M 2012. Can't Ask, Can't Tell: How Institutional Review Boards Keep Sex In The Closet. Contexts 11(2):28-33.

Israel T (2002) Studying Sexuality: Strategies for surviving stigma. Feminism and Psychology 12(2): 256-260

Kesler K (2002) Is a feminist stance in support of prostitution possible? An exploration of current trends. Sexualities 5(2): 219-235.

Kirby, R. and Corzine, J. (1981) The Contagion of Stigma: Fieldwork among Deviants. Qualitative Sociology 4(1): 3-20.

Klein C, Kennedy M A and Gorzalka B B (2008) Rape myth acceptance in men who completed the prostitution offender program of British Columbia. International Journal of Offender Therapy and Comparative Criminology 53(3): 305-315.

Kinnell H (2008) Violence and Sex Work in Britain. Cullompton: Willan Publishing.

Kingston S (2009) Community Perceptions of Men who buy Sex from Women. Unpublished Doctoral Thesis: University of Leeds.

Kingston S (2010) Intent to criminalize: Men who buy sex and prostitution policy in the UK. In: Hardy K, Kingston S and Sanders T (eds) New Sociologies of Sex Work, Farnham: Ashgate, 23-38.

Kingston S (forthcoming, 2013) Prostitution in the Community: Attitudes, Action and Resistance. London: Routledge. 
Lee D (1997) Interviewing Men: Vulnerabilities and dilemmas. Women's Studies International Forum 20(4): 553-564.

Link B and Phelan J (2001) Conceptualizing stigma. Annual Review of Sociology 27(3), 363-85.

Lowman J (2000) Violence and the Outlaw Status of (Street) Prostitution in Canada', Violence Against Women 6(9): 987-1011.

Maher L (2002) Don't leave us this way: ethnography and injecting drug use in the age

of AIDS. International Journal of Drug Policy 13, 311-325.

Mason J (2002) Qualitative Researching. London: Sage.

Mattley C (1997) Field research with phone sex workers: Managing researcher's emotions. In: Schwartz M (ed.) Researching Sexual Violence against Women: Methodological and Personal Perspectives. London: Sage, 101-114.

Melrose M (2002) Labour pains: some considerations on the difficulties of researching juvenile prostitution. International Journal of Social Research Methodology 5(4): 333-51.

Miller J and Schwartz M (1995) Rape myths and violence against street prostitutes. Deviant Behavior 16: 1-23.

Moreo E (1995) Rape in the Field: Reflections from a survivor. In: D. Kulick and M. Wilson (eds) Taboo: Sex, identity, and erotic subjectivity in anthropological fieldwork. London: Routledge, 166189.

Moran-Ellis J (1996) Close to home: the experience of researching child sexual abuse. In: Hester M, Kelly and Radford, J. (eds) Women, Violence and Male Power. Buckingham: Open University Press, 176-187.

O'Connell Davidson J and Layder D (1994) Methods Sex and Madness. London: Routledge..

Parker R and Aggleton P (2003) HIV and AIDS-related stigma and discrimination: a conceptual framework and implications for action. Social Science and Medicine 57, 13-24.

O’Neill M (1996) Prostitution and Feminism: Towards a Politics of Feeling. Cambridge: Polity Press. Pheterson G (1993) The Whore Stigma: Female Dishonor and Male Unworthiness, Social Text 37: 3964.

Pini B (2005) Interviewing men: gender and the collection and interpretation of qualitative data. Journal of Sociology 41(2): 201-216.

Plummer K (1995) Telling Sexual Stories: Power, Change and Social Worlds. London: Routledge.

Plumridge E, Chetwynd J, Reed A and Gifford S (1997) Discourses on emotionality in commercial sex: the missing client voice. Feminism and Psychology 7(2): 165-181. 
Presser L (2005) Negotiating power and narrative in research: Implications for feminist methodology. Signs: Journal of Women in Culture and Society 30(4): 2067-2090.

Rubenstein, S. (2004) Fieldwork and the Erotic Economy on the Colonial Frontier. Signs: Journal of Women in Culture and Society 29(4): 1041-1071.

Reavey P (1997) 'What do you do for a living then?' The Political Ramifications of Research Interests within Everyday Interpersonal Contexts. Feminism and Psychology 7(4): 553-558.

Sanchez Taylor J and O'Connell Davidson J (2010) Unknowable secrets and golden silence: reflexivity and research on sex tourism. In: Ryan-Flood R and Gill R (eds) Secrecy and Silence in the Research Process. London: Routledge, 42-53.

Sanders T (2005) Sex Work: A Risky Business. Cullompton: Willan Publishing.

Sanders T (2006) Sexing up the subject: methodological nuances in researching the female sex industry. Sexualities 9(4): 449-468.

Sanders T (2008) Paying for Pleasure: Men who buy sex. Cullompton: Willan Publishing.

Sanders T and Campbell R (2009) Why hate men who pay for sex? Investigating the shift to tackling demand and the calls to criminalise paying for sex. In: Munro V (ed.) Demanding Sex? Critical Reflections on the Supply/Demand Dynamic in Prostitution. Aldershot: Ashgate, 193-179.

Schoepf B (2001) International Aids research in Anthropology: Taking a Critical Perspective on the Crisis. Annual Review of Anthropology 30, 335-361

Scrambler G (2007) Sex work stigma: Opportunist migrants in London. Sociology 41(6): 1079-1096.

Sharpe K (2000) Sad, Bad and (sometimes) Dangerous to Know: Street Corner Research with Prostitutes, Punters and the Police. In: King R D and Wincup E (eds) Doing Research on Crime and Justice. Oxford: Oxford University Press, 363-372.

Shaver F (2005) Sex work research: methodological and ethical challenges. Journal of Interpersonal Violence 20(3): 296-319.

Stanley L and Wise S (1993) Breaking Out again: Feminist Ontology and Epistemology. London: Routledge.

Sullivan, B. (1995) Rethinking Prostitution. In: Caine, B. \& Pringle, R. (eds) (1995) Transitions: New Australian Feminisms. Allen \& Unwin: Sydney, 184-197.

Wahab S (2002) For their own good?: sex work, social control and social workers, a historical perspective. Journal of Sociology and Social Welfare 29(4): 39-57.

Walby, Kevin. (2010) Interviews as encounters: issues of sexuality and reflexivity when men interview men about commercial same sex relations. Qualitative Research 10(6):639-57.

Weitzer R (2005) A growing moral panic over prostitution and sex trafficking. The Criminologist: The Official Newsletter of the American Society of Criminology 30(5): 2-5. 
Zaplin R T (2008) Female offenders: Critical perspectives and effective interventions, 2nd edition. Sudbury, MA: Jones and Bartlett Publishers.

Zurbriggen E (2002) Sexual objectification by research participants: Recent experiences and strategies for coping. Feminism and Psychology 12(2): 261-268. 